\begin{tabular}{|l|l|}
\hline JURNAL ABDI MASYA & $\begin{array}{l}\text { Volume 1 Nomor } 1 \\
\text { November 2020 } \\
\text { pp 1-6 } \\
\text { Website: } \text { https://jurnal.sttw.ac.id/index.php/abma/about }\end{array}$ \\
\hline
\end{tabular}

\title{
PEMBEKALAN TEKNIK PENJUALAN PRODUK SECARA DIGITAL UNTUK PELAKU USAHA MIKRO KECIL MENENGAH KABUPATEN SUKOHARJO
}

\section{TRAINING OF DIGITAL SALES TECHNIQUE FOR SMALL MEDIUM ENTERPRISES IN SUKOHARJO DISTRICT}

\author{
Suharjanto $^{\left.1^{*}\right)}$, Stef Marwanto ${ }^{2)}$, Jarot Maryono ${ }^{3)}$ \\ 1), 2), 3) Program Studi Teknik Elektro, Sekolah Tinggi Teknologi Warga Surakarta, Surakarta, \\ Indonesia \\ *E-mail: harjantowijaya.atw@gmail.com
}

\begin{abstract}
ABSTRAK
Salah satu sektor bidang usaha yang menggerakkan ekonomi di pedesaan adalah Usaha Mikro kecil dan menengah (UMKM). Karena berdirinya UMKM baik berfungsi untuk mengentaskan pengangguran dalam hal ini menyedot kebutuhan akan tenaga kerja juga membantu perekonomiaan secara nasional. Dalam proses keberlangsungan hidup UMKM untuk menjalankan bisnisnya dengan baik dari proses penyediaan material (bahan) pembuatan, lokasi produksi, tenaga produksi, dapat berjalan dengan baik. Namun dalam salah satu faktor marketing atau pemasaran produk masih dilakukan secara manual (konvensional) dalam hal ini dilakukan secara tatap muka langsung dengan konsumen atau pembeli, sehingga segmen pasar masih terlalu sempit. Sehingga untuk memberikan salah satu solusi dari kendala di atas, Penulis bersama rekan staf pengajar / dosen jurusan teknik elektro, serta himpunan mahasiswa Jurusan Teknik Elektro (HMJTE) Sekolah Tinggi Teknologi Warga Surakarta memberikan salah satu solusi dengan mengadakan pelatihan pembekalan untuk pelaku UMKM Kabupaten Sukoharjo. Materi pelatihan untuk memberikan solusi kendala di atas penulis memberikan materi pembekalan pola teknik sistem penjualan produk secara digital untuk pelaku usaha mikro kecil menengah kabupaten sukoharjo. Proses pemasaran dan penjualan produk UMKM secara digital atau online dengan menggunakan kedua metode teknik di atas dapat menembus pasar moderen maupun pasar luar negeri. Hasil akhir dari pelatihan ini para pelaku usaha UKM/UMKM mampu menambah pengetahuan membuat nama produk (keyword) dengan baik dan familiar, serta peserta mengalami peningkatan yaitu dapat merencanakan dan membuat keyword untuk nama website yang tepat sasaran dalam arti nama website banyak dicari oleh pelanggan media digital. Para peserta sekarang dapat membuat website dengan baik untuk iklan produknya dan juga peserta mampu memasarkan produk yang dihasilkan dengan media online dengan nama website yang menarik. Peserta juga berhasil menempatkan nama website produk hasil UKM/UMKM dalam halaman utama Google dengan pencari dalam ukuran waktu 0.61 detik sebanyak 2.880.000.
\end{abstract}

Kata Kunci: konvensional, marketing, UMKM, website

Submit : 16 Juli 2020, Accepted : 18 November 2020 Publish : 24 November 2020

\section{PENDAHULUAN}

Marketing atau Pemasaran adalah salah satu alur dalam sistem perdagangan atau proses bisnis. Upaya peningkatan jumlah penjualan produk, para pelaku usaha berlomba lomba untuk untuk menguasai ilmu atau strategi teknik pemasaran yang handal untuk mendongkrak di dalam penjualan produk yang dihasilkan. Pemasaran model konvensional cenderung menempatkan hasil produknya dalam display atau toko permanen yang ditawarkan melalui bagian penjualan secara lisan atau verbal. Dengan 
demikian pemasaran secara konvensional area jangkauan untuk pembeli menjadi sempit. Sehingga, untuk mengenalkan produk yang dihasilkan juga dalam pelanggan yang terbatas.

Para pelaku usaha UKM/UMKM dalam memasarkan teknik pemasaran secara digital masih menggunakan media Facebook atau WhatsApp yang jumlah pengikutnya juga terbatas pada lingkup saudara atau teman saja. Teknik ini juga kesulitan untuk memasarkan produk tersebut secara luas. Solusi dari identifikasi permasalahan di atas, maka perlu adanya teknik pemasaran secara digital yang mampu mendekatkan dengan konsumen dalam jumlah yang tidak terbatas bahkan menembus pasar domestik juga pasar Internasional. Oleh karena itu, dibuat suatu sistem pemasaran dengan menggunakan media iklan melalui Website. Teknik pemasaran menggunakan media Website ini harus menguasai pengetahuan cara atau metode teknik riset memilih nama Website serta teknik menempatkan Website/Promosi pada halaman utama Google. Selain itu, strategi dalam menentukan Kata Kunci (Keyword) untuk bisa menempatkan Website/Promosi pada halaman utama Google harus dikuasai supaya marketing secara digital dapat berjalan maksimal sehingga akan didapatkan hasil penjualan produk meningkat. Konsep tentang pengabdian ini pernah dilakukan dengan model yang berbeda.

Promosi merupakan fungsi pemasaran yang fokus untuk mengkomunikasikan program pemasaran secara persuasif kepada target pelanggan atau calon pelanggan (audience) untuk mendorong terciptanya transaksi pertukaran antara perusahaan dengan audience [1]. Website adalah fasilitas internet yang menghubungkan alam lingkup lokal maupun jarak jauh [2]. Hal ini dikarenakan website berisi kumpulan halaman yang menampilkan informasi data teks, data gambar diam atau gerak, data animasi, suara, video atau gabungan semuanya baik yang bersifat statis maupun dinamis. Menurut peneliti sebelumnya bahwa penggunaan teknik Search Engine Optimization (SEO) lebih mudah mencapai peringkat teratas dalam penerapannya pada website [3].

Tujuan dari kegiatan pengabdian kepada masyarakat yang telah dilaksanakan melalui kegiatan pelatihan dan pembekalan pola sistem penjualan produk UMKM/UKM adalah pertama membantu para pelaku UMKM untuk membentuk market place. Kedua membantu pelaku UMKM untuk memasarkan produk hasil produksinya ke pasar modern maupun pasar luar negeri. Ketiga membantu pelaku UMKM untuk memahami teknologi pemasaran atau penjualan produksi secara digital.

\section{METODE}

Metode dalam pola pengabdian ini yaitu metode pelatihan secara tatap muka langsung antara pengajar dengan peserta pelatihan dalam waktu 1 hari di Laboratorium R\&D Jurusan Teknik Elektronika Sekolah Tinggi Teknologi Warga Surakarta. Urutan pelaksanaan kegiatan ini meliputi pertama mengajarkan teknik domain yaitu teknik membuat nama unik yang diberikan untuk mengidentifikasi nama server computer seperti web server atau email server yang digunakan dalam jaringan komputer atau internet. Kedua mengajarkan membuat keyword yang familiar serta mudah diingat. Ketiga mengajarkan teknik dalam memilih nama website promosi produk UKM/UMKM. Keempat mengajarkan teknik cara menempatkan nama website di halaman utama Google.

\section{HASIL DAN PEMBAHASAN}

Program Kegiatan Kepada Masyarakat ini merupakan hasil kerjasama antara Program Studi Teknik Elektronika Sekolah Tinggi Teknologi Warga Surakarta dengan Dinas Koperasi Usaha Kecil dan Menengah Kabupaten Sukoharjo yang berlangsung di Sekolah Tinggi Teknologi Warga Surakarta. Pelaksanaan kegiatan pengabdian ini berupa 
pelatihan cara membuat iklan produk UKM/UMKM dengan metoda secara tatap muka langsung antara pengajar dengan peserta pelatihan (para pelaku UKM/UMKM Kab Sukoharjo) di Laboratorium Komputer R\&D Jurusan Teknik Elektronika. Gambar 1 menunjukkan pimpinan kampus Sekolah Tinggi Teknologi Warga Surakarta dengan Kepala Dinas Koperasi Usaha Kecil dan Menengah Kabupaten Sukoharjo beserta Peserta Pelatihan.

Pelaksanaan pelatihan diawali dengan presensi peserta pelatihan diteruskan pemaparan awal materi pelatihan menggunakan metode tatap muka langsung antara pengajar dengan peserta pelatihan dengan media LCD, proyektor, sound system, komputer, laptop seperti ditunjukkan pada Gambar 2. Tabel 1 menunjukkan peserta $\mathrm{UKM} / \mathrm{UKM}$ yang mengikuti pelatihan beserta produknya.

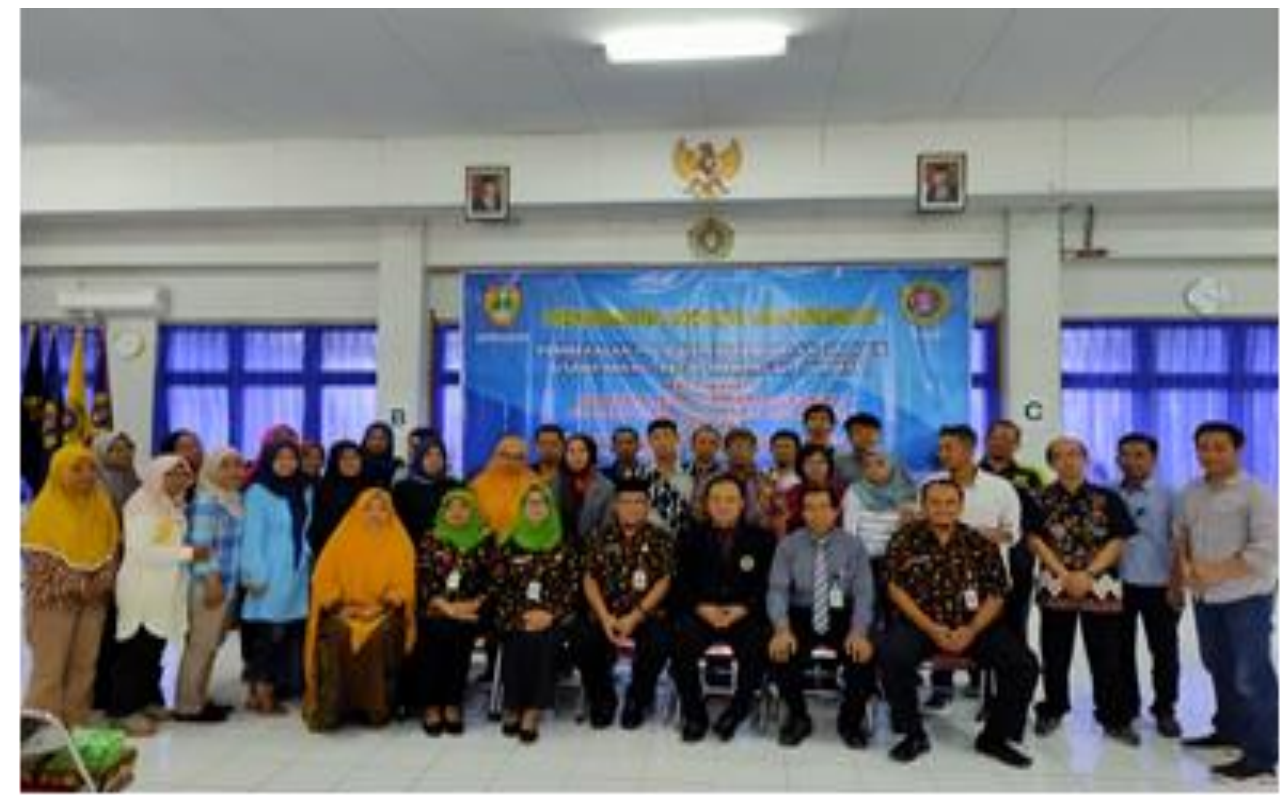

Gambar 1. Foto Pimpinan Kampus dengan Kepala Dinas dan Peserta

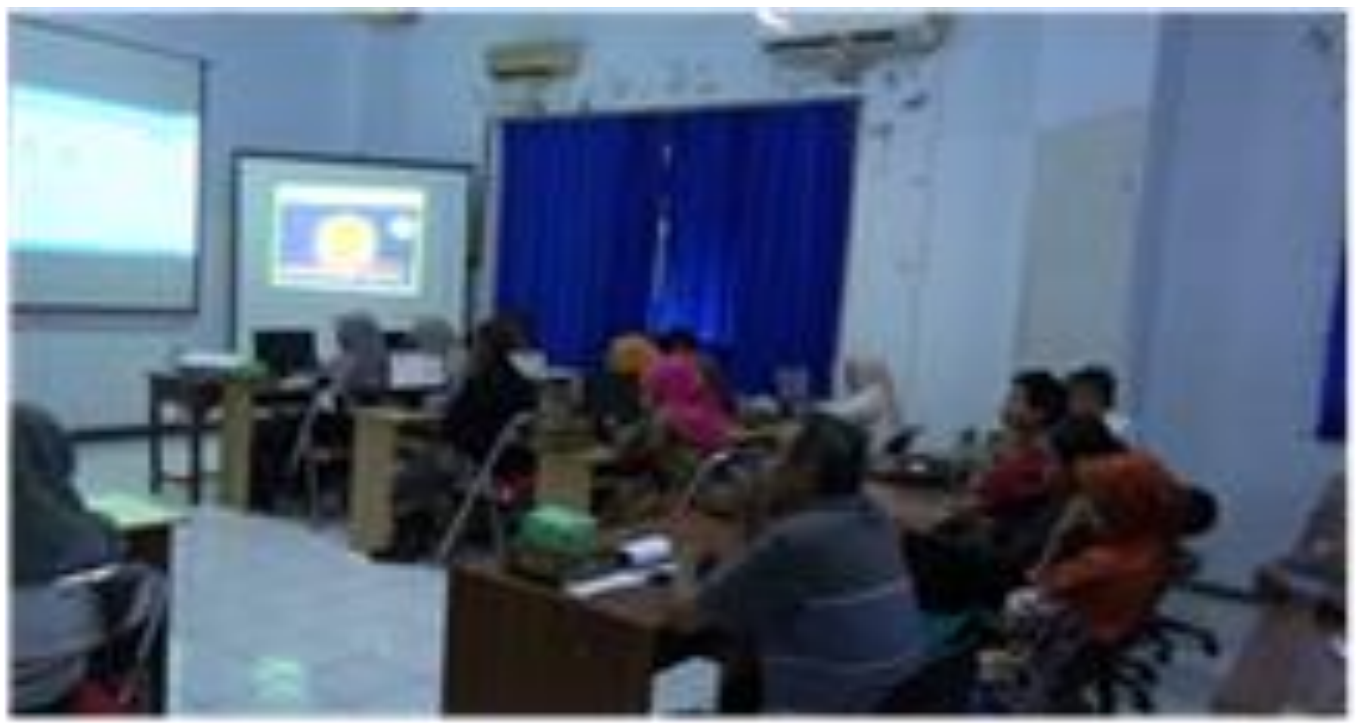

Gambar 2. Pelaksanaan Pelatihan Pengabdian 
Tabel 1. Peserta UKM/UKM yang mengikuti pelatihan beserta produknya

\begin{tabular}{|c|c|}
\hline Nama Peserta & Jenis UKM/UMKM \\
\hline Abdullanh Ibnu M & Sukoharjoisme Store \\
\hline Afifah Tri M & Aksesoris dan Souvenir \\
\hline Andi Wibowo & Kerajinan Rotan \\
\hline Anis Widya M & Spezia Wedang Rempah \\
\hline Bagas Tri M & Lightstick dan Jasa Digital \\
\hline Dewi Ambarsari & Handycraft \\
\hline Dewi $\mathrm{W}$ & Jamu 3 Putri \\
\hline Ellyatmi & Sosis Solo \\
\hline Firdaus & Deodoran Spray \\
\hline Galih P & Batik Sekar Tanjung \\
\hline Hanif Abadi & Batik \\
\hline Haryoko & Graram Gardium \\
\hline Lilik Juariyah & Nisrina Collection Tas \& Souvenir \\
\hline Lindwati & Herlins Collection \\
\hline Nur Mustofa & Bakery \\
\hline Nuryanto & Ternak Lele dan Magot \\
\hline Poedyoko & Percetakan Map raport K13 \\
\hline Rina Wijayaten & Produk Batik Melati Wijaya \\
\hline Romiyah & Kue dan Tart SRB \\
\hline Sri Rejeki & Makanan Kering \\
\hline Sriyanti & Difakit Minuman \\
\hline Sulardi & Barang Antik/Lawasan \\
\hline Sulastri & Jamur Krispi Anak Ragil \\
\hline Suratno & Atmo Barokah \\
\hline Tien Pitoyo & Mie Throprak Mbak Tien \\
\hline Tresni Hidayati & Kripik Tresni \\
\hline Triyono & Peyek Lombok Ijo \\
\hline Umi Listiyani & Fashion Aurora Hijab \\
\hline Uswatun $\mathrm{K}$ & Berkah Snack Ubi Madu \\
\hline Zakki Ryan & Zakki Niki Craft \\
\hline
\end{tabular}

Pelaksanaan pelatihan ini dimulai dengan memberikan pemaparan singkat memberikan latar belakang tentang kenapa pelatihan untuk pelaku UKM/UMKM harus dilakukan. Kegelisahan dari para pelaku usaha UKM/UMKM mengenai kesulitan dalam mengenalkan produk kepada masyarakat secara luas dikarenakan marketing hanya dijalankan secara offline atau manual. Sehingga, pangsa pasar yang dikuasai sangat sempit. Selain itu, bagaimana para pelaku UMKM untuk membentuk sebuah market place dan juga bagaimana para pelaku UKM/UMKM untuk memasarkan produk hasil produksinya ke pasar modern maupun pasar luar negeri.

Setelah menampung apa yang menjadi pertanyaan dan permasalahan dari para peserta, selanjutnya dilakukan pelatihan untuk menjawab permasalahan di atas. Metode tatap muka langsung ini menjadi metode yang terbaik, karena dengan metode tatap muka secara langsung hubungan secara personal antara pengajar dengan peserta lebih menyatu sehingga materi pelatihan mudah untuk disampaikan. Pertanyaan dari peserta tentang materi pelatihan bisa cepat ditanggapi secara cepat dan tepat. 
Pelaksanaan pengabdian selanjutnya adalah memberikan pemaparan tentang teknik domain yaitu semacam teknik membuat nama unik yang diberikan untuk mengidentifikasi nama server computer seperti web server atau email server yang digunakan dalam jaringan komputer atau internet. Teknik domain ini memberikan efek yang sangat signifikan kepada pengguna atau pelanggan yang mencari nama server tanpa mengingat angka atau istilah menjadi IP (Indeks Protocol). Metode teknik domain dapat membuat keyword yang familiar serta mudah diingat. Teknik dalam memilih nama website sangat menentukan dalam keberhasilan promosi produk UKM/UMKM. Sehingga, teknik memilih nama website dapat dimulai dengan melakukan riset kata kunci, untuk mendapatkan kata kunci nama website yang bagus dan tepat sasaran.

Iklan merupakan pola membuat keyword untuk nama produk, teknik strategi pemasaran/promosi produk yang dihasilkan secara digital (online). Teknik metode riset dilakukan untuk memilih nama website untuk nama usaha, serta teknik menempatkan promosi pada halaman utama Google.

Teknik dalam memilih nama website sangat menentukan dalam keberhasilan promosi produk UKM/UMKM. Teknik memilih nama website dapat dimulai dengan melakukan riset kata kunci untuk mendapatkan kata kunci nama website yang bagus dan tepat sasaran. Teknik urutan membuat nama/domain juga keyword adalah sebagai berikut:

1. Membuat nama yang menimbulkan energi positif thinking supaya nama produk atau tagline selalu terekam dipelanggan.

2. Siapkan atau pastikan tema bisnis serta produksinya sehingga arah atau target siapa pembeli maupun area pemasaran atau sasaran yang dituju bisa tepat.

3. Siapkan nama domain anda 5 - 10 kata supaya mudah diingat (contoh jamur renyah.com)

4. Nama domain mudah diketik seperti "jamur renyah.com" sehingga dengan metode teknik domain akan dihasilkan nama website yang familiar atau disebut brand produk.

Teknik keyword ini menjadi metode paling ampuh untuk membuat brand/nama produk melalui website yang terkenal dan mudah diingat. Hasil akhir dari pelatihan ini para pelaku usaha UKM/UMKM mampu menambah pengetahuan membuat nama produk (keyword) dengan baik dan familiar, serta peserta mengalami peningkatan yaitu dapat merencanakan dan membuat keyword untuk nama website yang tepat sasaran dalam arti nama website banyak dicari oleh pelanggan media digital. Para peserta sekarang dapat membuat website dengan baik untuk iklan produknya dan juga peserta mampu memasarkan produk yang dihasilkan dengan media online dengan nama website yang menarik. Peserta juga berhasil menempatkan nama website produk hasil UKM/UMKM dalam halaman utama Google dengan pencari dalam ukuran waktu 0.61 detik sebanyak 2.880 .000 .

\section{SIMPULAN}

Kegiatan Pelaksanaan pengabdian kepada masyarakat sudah berlangsung dengan baik. Manfaat yang didapatkan dari pengabdian kepada masyarakat ini adalah peserta dapat membuat nama dari hasil produk pelaku UKM/UMKM yang dibuat dengan kata keyword yang menarik dalam website sehingga lebih mudah dikenal dan paling banyak dicari di halaman utama Google. Nama website produk hasil UKM/UMKM yang sudah dibuat oleh peserta pada halaman utama Google dapat mencapai sebanyak 2.880.000 pencarian hanya dalam ukuran waktu 0.61 detik. Dengan demikian, permintaan akan produk jadi meningkat sehingga penjualan secara marketing digital dapat mendekatkan pada market Place. 


\section{UCAPAN TERIMA KASIH}

Terima kasih yang sebesar besarnya kami haturkan kepada Kepala Dinas Koperasi UKM Kab.Sukoharjo beserta staf, juga kepada Ketua Sekolah Tinggi Teknologi Warga Surakarta, rekan rekan Dosen Teknik Elektronika Sekolah Tinggi Teknologi Warga Surakarta, serta HMJ Jurusan Teknik Elektronika, seluruh peserta pelatihan juga pada pihak (individu atau organisasi) yang telah berjasa dalam membantu pengabdian.

\section{DAFTAR PUSTAKA}

[1] H. Ali, "Marketing, Cetakan Pertama, Media Pressdindo," ed: Yogyakarta, 2013.

[2] L. Hakim and U. Musalini, "Cara Cerdas Menguasai Layout, Desain dan Aplikasi Web," Jakarta: PT Elex Media Komputindo, 2004.

[3] D. Edi and V. R. Sjofyan, "2. Sistem Informasi Penyewaan Properti Berbasis C2C," Jurnal Sistem Informasi, vol. 7, 2015. 